\title{
Incidence of Coronary Artery Disease (CAD) Death in Diabetic Patients: Our Experience at a Tertiary Care Hospital
}

\author{
Authors

\section{Shobhitendu Kabi ${ }^{1}$, Siba Prasad Dalai ${ }^{1 *}$, Mahesh Chandra Sahu ${ }^{2}$}

${ }^{1}$ Department of Medicine, IMS and SUM Hospital, ${ }^{2}$ Directorate of Medical Research, IMS and SUM Hospital. Siksha 'O' Anusandhan University, K-8, Kalinga Nagar, Bhubaneswar-751003, Odisha, India *Corresponding Author

Dr Siba Prasad Dalai

Assistant Professor, Department of Medicine, IMS and SUM Hospital, Bhubaneswar, Odisha, India Email:drsibadalai@gmail.com

\begin{abstract}
Introduction: Diabetes is a major challenge India is facing today. Cause of death in diabetes in the globe points towards cardiovascular diseases as commonest. However, infection is also a major contributor to mortality in diabetics in India as some of the previous Indian studies suggest.

Objective: To find out the mortality pattern in coronary artery disease (CAD) in diabetics visa vis those without diabetes in a tertiary care centre in Eastern India.

Methods: It is a retrospective study, in which data of in hospital death with CAD in 5 years (2014-2017) were collected from our Hospital Records Department. These data were tabulated with respect to age groups and co-morbidities.

Results: A total number of 284 patients died with CAD. Among them 188 were with diabetes and 96 were without diabetes. It is statistically significant with $P=0.03$. Whereas male death (193) was predominate over female (91), with ratio 2:1. It is statistically significant with $P=0.02$. The death due the CAD with respect to duration of its diagnosis in those with diabetes was compared to those without diabetes were also significant with $P=0.01$. The co-existence of infection/sepsis was also compared but it was not statistically significant.

Conclusion: In this study it is found that co-morbidity of diabetes is a major deciding factor in final outcome (death) of CAD. The death in males with CAD was higher than the age matched females. It may be due to relative protection against $C A D$ in females of menstruating age.

Keywords: Diabetes mellitus; CAD; Morbidity; Mortality; Retrospective.
\end{abstract}

\section{Introduction}

Coronary artery disease (CAD) is a major cause of death in Western countries, and it is becoming a major cause of death in developing countries. This increase may be due to the rising prevalence of many CAD risk factors, such as diabetes, which is one of the most important of these risk factors.
The prevalence of diabetes is increasing globally, and it has reached pandemic levels in the Middle East and worldwide. ${ }^{1}$

Diabetes as a risk factor for CAD The prevalence of DM is increasing globally, and the International Diabetes Federation (IDF) estimated that there were 387 million people with DM in 2013, and 
this incidence is expected to rise to 592 million by 2035. An estimated 1 in 10 people have DM in the Middle East and North Africa (MENA) region. ${ }^{2}$ Six of the top ten countries with a high estimated prevalence of DM were Arab countries in the 2011 IDF global estimate: Kuwait, Lebanon, Qatar, KSA, Bahrain and United Arab Emirates. ${ }^{3}$ Three of the top 10 countries with a high estimated prevalence of DM were Arab countries in the updated 2014 IDF estimate: KSA, Kuwait and Qatar. ${ }^{2}$ (Table 1 and 2). The overall prevalence of DM was $23.7 \%$, (26.2\% in males \& $21.5 \%$ in females) in a study of the prevalence of diabetes in $\mathrm{KSA}^{4}{ }^{4}$ which was part of the Coronary Artery Disease in Saudis Study (CADISS), ${ }^{5}$ and the impaired fasting blood glucose was $14.1 \%$ for males and females combined. A total of $27.9 \%$ of diabetics were unaware of having diabetes, ${ }^{4}$ and $34 \%$ of diabetic patients were hypertensive compared to $21.4 \%$ without DM ( $\mathrm{P}<0.001) .24$ These factors further contribute to the risk of CAD in the KSA population. CADISS is a national community-based study th at examined 17,232 KSA subjects aged 30e70 years from randomly selected households. The primary objective was to estimate the prevalence of CAD and its risk factors in KSA. The overall prevalence of $\mathrm{CAD}$ was $5.5 \%(6.6 \%$ in males, $4.4 \%$ in females). ${ }^{4}$

The overall prevalence of CAD among patients with diabetes is higher than in non-diabetic patients and may be as high as $55 \%$ among patients with diabetes. ${ }^{5}$ Furthermore, CAD represents the leading cause of death in patients with diabetes. ${ }^{6,7}$ Most of the published studies present data on type 2 diabetes (more than $90 \%$ of all diabetic patients). Less data is available for type 1 diabetes. Therefore, most of our statements also focus on type 2 diabetes. Since diabetics often present with silent myocardial ischaemia, they lack an important clinical "warning symptom" of their CAD. Data from the Framingham Study suggest that asymptomatic patients with multiple risk factors have an annual cardiac death rate of approximately $3 \%{ }^{6,8}$
In this study we evaluated the magnitude of risk of CAD leading death in different genders, age groups and duration of diagnosis DM.

\section{Materials and Method}

In this retrospective study all the data were collected from medical records department where data were stored both in register and in computer. The data of all the death cases due to CAD were documented and analysed. The death of the CAD Patients with or without diabetes were analysed and evaluted. The association of diabetes in patients dying of CAD was analysed. The duration of the CAD before death in respect of those with diabetes and those without diabetes was also compared. We tried to evalaute the association of the length of the duration from diagnosis to death in CAD in case of diabetes as compared with those without diabetes. Apart from diabetes, the association of infection in the fatal cases of CAD was also evaluated. The data generated was analysed with the help of SPSS 20 Version to know the statistical significance.

\section{Results}

The study group was classified according their age groups. It was revealed that the younger age group had less number of death age comparative older age group (Table-1). In the younger age group, males are affected more than females. This difference narrows down in higher age groups. Over all it is male predominant (Table-1). The death of CAD Patient due to diabetes had more than the patient of $\mathrm{CAD}$ without diabetes. In statistically it is significant $\mathrm{P}=0.03$ with t-test (Table-1)

The duration of the CAD have classified into seven groups in found the patient with more duration of $\mathrm{CAD}$ were highly predominant to death. A comparison t-test between the duration of CAD with diabetes and without diabetes were compare. Where it was reveal that the duration of CAD with $\mathrm{DM}$ is more significant at $\mathrm{P}=0.01$ (Table-2, Fig 1) 
Table 1 Death of patients with and without DM with respect to age groups.

\begin{tabular}{|l|c|c|c|c|c|c|}
\hline \multirow{2}{*}{$\begin{array}{l}\text { Age } \\
\text { group }\end{array}$} & \multicolumn{3}{|c|}{ CAD with DM } & \multicolumn{3}{c|}{ CAD without DM } \\
\cline { 2 - 7 } & Male & Female & Total & Male & Female & Total \\
\hline $20-29$ & 2 & 0 & 2 & 0 & 0 & 0 \\
\hline $30-39$ & 9 & 2 & 11 & 2 & 2 & 4 \\
\hline $40-49$ & 18 & 9 & 27 & 7 & 3 & 10 \\
\hline $50-59$ & 43 & 13 & 56 & 11 & 5 & 16 \\
\hline $60-69$ & 29 & 15 & 44 & 17 & 10 & 27 \\
\hline$\geq 70$ & 32 & 16 & 48 & 23 & 16 & 39 \\
\hline Total & 133 & 55 & 188 & 60 & 36 & 96 \\
\hline
\end{tabular}

Table 2 Duration of diagnosis with respect to death due to CAD

\begin{tabular}{|l|c|c|c|c|c|c|}
\hline \multirow{2}{*}{$\begin{array}{l}\text { Detection of } \\
\text { CAD }\end{array}$} & \multicolumn{3}{|c|}{ CAD with DM } & \multicolumn{3}{c|}{ CAD without DM } \\
\cline { 2 - 7 } & Male & Female & Total & Male & Female & Total \\
\hline$<1$ month & 13 & 3 & 16 & 2 & 1 & 3 \\
\hline 1-12month & 9 & 3 & 12 & 5 & 2 & 7 \\
\hline 1-5 years & 10 & 4 & 14 & 9 & 3 & 12 \\
\hline 6-10 year & 17 & 11 & 28 & 12 & 7 & 19 \\
\hline 11-15 years & 16 & 13 & 29 & 17 & 7 & 24 \\
\hline 16-20years & 21 & 7 & 28 & 14 & 7 & 21 \\
\hline$>20$ years & 33 & 2 & 35 & 15 & 21 & 36 \\
\hline Total & 119 & 43 & 162 & 74 & 48 & 122 \\
\hline
\end{tabular}

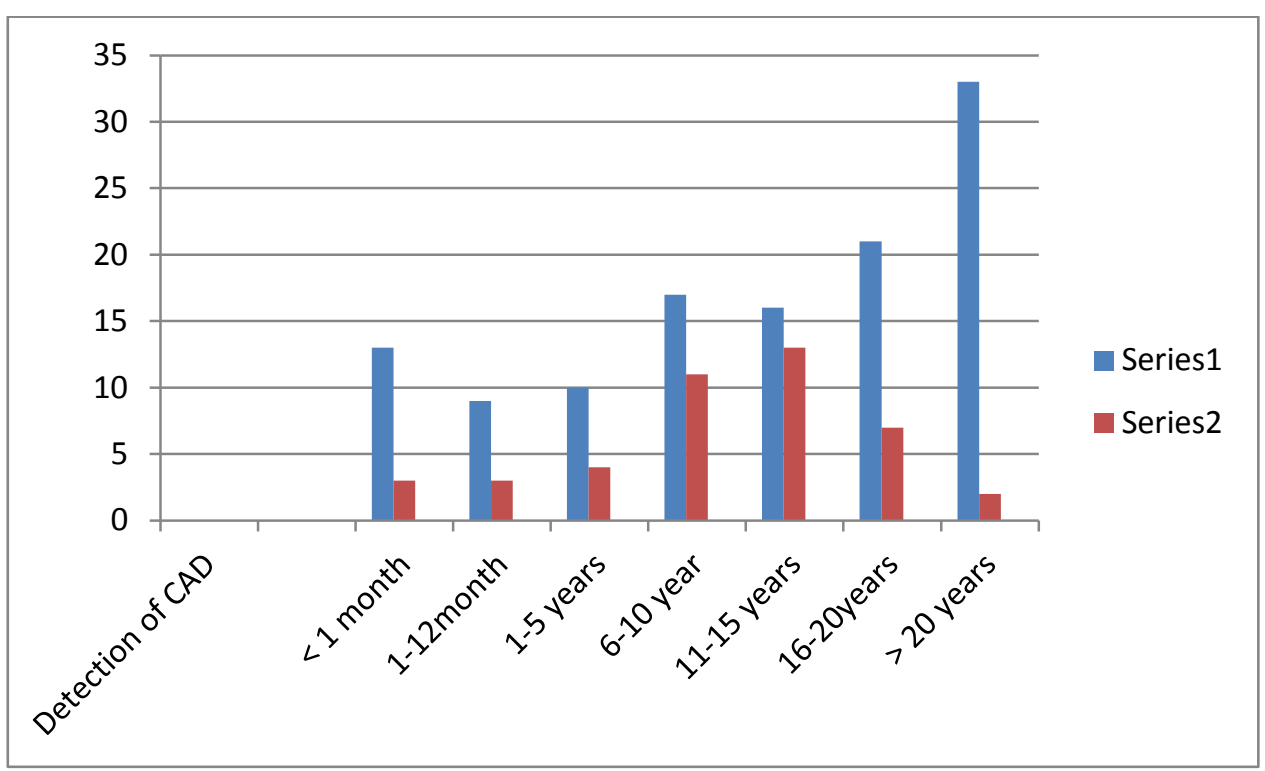

Fig 1 Death of patients with respect to duration of diagnosis

Infection is also a major role for death so we have compare the CAD Patient with against the CAD Patient without infection. The total number of death of CAD Patient with infection and without infection there 159 and 125 respectively. Though the number of death of CAD Patient infection higher than the CAD Patient without infection but statistically it is in significant at $\mathrm{P}=0.16$ (Table-3)

Table 3 Death due to CAD with and without infections.

\begin{tabular}{|l|c|c|c|c|c|c|}
\hline \multirow{2}{*}{$\begin{array}{l}\text { Age } \\
\text { group }\end{array}$} & \multicolumn{3}{|c|}{ CAD with Infections } & \multicolumn{3}{c|}{ CAD without Infections } \\
\cline { 2 - 7 } & Male & Female & Total & Male & Female & Total \\
\hline $20-29$ & 4 & 0 & 4 & 2 & 0 & 2 \\
\hline $30-39$ & 5 & 0 & 5 & 11 & 2 & 13 \\
\hline $40-49$ & 18 & 3 & 21 & 13 & 5 & 18 \\
\hline $50-59$ & 30 & 23 & 53 & 28 & 9 & 37 \\
\hline $60-69$ & 32 & 17 & 49 & 20 & 19 & 39 \\
\hline$\geq 70$ & 23 & 4 & 27 & 7 & 9 & 16 \\
\hline Total & 112 & 47 & 159 & 81 & 44 & 125 \\
\hline
\end{tabular}




\section{Discussion}

This study analyzed the relationship of hospital death due to CAD in those without diabetes and those with diabetes for a period of 4 years. Participants were of both sexes and aged 20years and above. It was found that approximately half of the study population had dyslipidemia $(45.6 \%)$ and approximately half had obesity (BMI >25 $\mathrm{kg} / \mathrm{m}^{2} 47.6 \%$ ). About one fifth of the study population was hypertensive $(21 \%)$ and one sixth had DM (16\%). Two or more CAD risk factors were identified in $78.6 \%$ of participants, which indicates that there is a large population who will develop CAD in the near future. The present results can be compared with the findings in 739 subjects (451 men and 288 women) of the Jaipur Heart Watch-5 study by Gupta et al. ${ }^{9}$ That study found that $46.2 \%$ of men and $50.7 \%$ of women were overweight or obese. The prevalence of hypertension was $39.5 \%$ in men and $24.6 \%$ in women, that of diabetes was $15.5 \%$ of men and in $10.85 \%$ of women, and that of dyslipidemia was $33 \%$ in men and $32.7 \%$ in women. Similar results were found by a study by Prabhakaran et $\mathrm{al}^{10}$ among men working in an industry in northern India. A high serum total cholesterol/HDL ratio was found in $62 \%$ of the population, overweight in $47 \%$, hypertension in $30 \%$ and diabetes in $15 \%$. Prabhakaran et al also showed that $47 \%$ of their subjects had at least two CAD risk factors, compared with $78.6 \%$ with two or more CAD risk factors in the present study. Another study in 2008 by Mohan and Deepa showed the following prevalences of major risk factors for cardiovascular disease: diabetes $11.9 \%$, hypertension $25.4 \%$, dyslipidemia $40.2 \%$, hypertriglyceridaemia $28.3 \%$, overweight $60.2 \%$ ${ }^{10-15}$ An increasing prevalence of impaired glucose tolerance and diabetes in urban residents of Chennai was reported by Ramchandran et al. ${ }^{16}$ In 2002, Gupta et al showed that smoking and low physical activity levels were widespread in 20-39year-old urban adults. ${ }^{17}$ Another important independent risk factor for CAD is a family history of $\mathrm{CAD}$, as reported by Goel et al in
2003. ${ }^{18}$ Our study has clearly shown that among the middle class Indian population, there is a high prevalence of diabetes, which are CAD risk factors. CAD has a multifactorial aetiology, with many of the risk factors being influenced by lifestyle. Rapid change in dietary habits coupled with decreased physical activity in India as consequence of urbanisation may partly explain the increase in CAD. India is experiencing an epidemiological transition with high rates of urbanisation. ${ }^{19}$ This has led to economic improvement, the consequences of which are increased fast food consumption and tobacco usage, and decreased physical activity. With the introduction of an era of refined foods, sugar and hydrogenated oils, the traditional high complex carbohydrate, high fibre and low fat diet has been replaced by a diet rich in fats and simple sugars low in dietary fibre. ${ }^{19}$ One of the effects of this transition is a shift in the disease spectrum from communicable to non-communicable diseases, particularly CAD and diabetes. ${ }^{20-22}$ More importantly, CAD is affecting young Indians who comprise the productive workforce. The incidence of CAD in young Indians is $12-16 \%$, which is higher than in other ethnic groups worldwide. Lack of awareness of the preventable risk factors and ignorance of the disease are also important factors responsible for the increasing rate of CAD among Indians. ${ }^{23-28}$ In literatures it was found that $16 \%$ of diabetes, $5.6 \%$ were diagnosed during the study. This shows that awareness and control of hypertension and diabetes was poor in the study population, indicating low detection and poor management of major CAD risk factors. Prevention and control of the risk factors for CAD such as diabetes can reduce the rate of CAD death.

\section{Conclusions}

The present study will be helpful to assess the magnitude of the problem of CAD in association with diabetes mellitus and thereby making policies to take preventive and early therauptic intervention to prevent early death 


\section{Reference}

1. Elhadd TA, Al-Amoudi AA, Alzahrani AS. Epidemiology, clinical and complications profile of diabetes in Saudi Arabia: a review. Ann Saudi Med 2007; 27(4): 241e250.

2. Guariguata L, Whiting DR, Hambleton I, Beagley J, Linnenkamp U, Shaw JE. Global estimates of diabetes prevalence for 2013 and projections for 2035. Diabetes Res Clin Pract 2014; 103(2): 137e149.

3. Whiting DR, Guariguata L, Weil C, Shaw J. IDF diabetes atlas: global estimates of the prevalence of diabetes for 2011 and 2030. Diabetes Res Clin Pract 2011; 94(3): $311 \mathrm{e} 321$.

4. Al-Nozha MM, Al-Maatouq MA, AlMazrou YY, Al- Harthi SS, Arafah MR, Khalil MZ, et al. Diabetes mellitus in Saudi Arabia. Saudi Med J 2004; 25(11): $1603 \mathrm{e} 1610$.

5. Al-Nozha MM, Arafah MR, Al-Mazrou YY, Al- Maatouq MA, Khan NB, Khalil MZ, et al. Coronary artery disease in Saudi Arabia. Saudi Med J 2004; 25(9): $1165 \mathrm{e} 1171$.

6. Al-Nozha MM, Abdullah M, Arafah MR, Khalil MZ, Khan NB, Al-Mazrou YY, et al. Hypertension in Saudi Arabia. Saudi Med J 2007; 28(1): 77e84.

7. Kannel WB, McGee DL. Diabetes and glucose tolerance as risk factors for cardiovascular disease: the Framingham study. Diabetes Care 1979;2:120-6.

8. Kannel WB, McGee DL. Diabetes and cardiovascular disease: the Framingham Study. JAMA 1979;241:2035-8.

9. Gupta AK, Bharadwaj A, Ashotra S, et al. Feasibility and training of multipurpose workers in detection, prevention and control of coronary artery disease in applebelt of Shimla hills. South Asian J Prev Cardiol. 2002;6:17e22.

10. Joshi R, Cardona M, Iyengar S, et al. Chronic disease s now a leading cause of death in rural India: mortality data from the Andhra Pradesh Rural Health Initiative. Int $\mathrm{J}$ Epidemiol. 2006;35: $1522 \mathrm{e} 1529$.

11. Ezzati M, Lopez AD, Rodgers A, et al. Comparative Quantification of Health Risks. Global and Regional Burden of Disease Attributable to Major Risk Factors. Geneva: World Health Organisation; 2004.

12. Enas EA, Yusuf S, Mehta J. Prevalence of coronary artery disease in Asian Indians. Am J Cardiol. 1992;70:945e949.

13. Yusuf S, Hawken S, Ounpuu S, et alThe INTERHEART Study Investigators. Effect of potentially modifiable risk factors associated with myocardial infarction in 52 countries (the INTERHEART Study): case control study. Lancet. 2004;364:937e952.

14. O’Donnell MJ, Xavier D, Liu Lisheng, et al. Risk factors for ischaemic and intracerebral haemorrhagic stroke in 22 countries (the INTERSTROKE study): a caseecontrol study. Lancet. 2010;376: $112 \mathrm{e} 123$.

15. Bhatnagar D, Anand IS, Durrington PN, et al. Coronary risk factors in people from the Indian subcontinent living in west London and their siblings in India. Lancet. 1995;345:405e409.

16. King H, Aubert RE, Herman WH. Global burden of diabetes, 1995e2025: prevalence, numerical estimates, and projections. Diabetes Care. 1998;21: $1414 \mathrm{e} 1431$.

17. Ramachandran A. Epidemiology of diabetes in Indiadthree decades of research. J Assoc Physicians India. 2005;53:34e38.

18. Reddy KS, Shah B, Varghese C, Ramadoss A. Responding to the challenge of chronic diseases in India. Lancet. 2005;366:1744e1749.

Beaglehole R, Yach D. Globalization and the prevention and control of non- 
communicable diseases: the neglected chronic diseases of adults. Lancet. 2003;362:903e908.

19. Emberson JR, Whincup PH, Morris RW, Walker M. Social class differences in coronary heart disease in middle-aged British men: implications for prevention. Int J Epidemiol. 2004;33:289e296.

20. Singh RB, Sharma JP, Rastogi V, et al. Prevalence of coronary artery disease and coronary risk factors in rural and urban populations of north India. Eur Heart J. 1997; 18:1728e1735.

21. Gupta R, Gupta VP, Sarna M, et al. Prevalence of coronary heart disease and risk factors in an urban Indian population: Jaipur Heart Watch-2. Indian Heart J. 2002;54:23e30.

22. Thankappan KR, Shah B, Mathur P, et al. Risk factor profile for chronic noncommunicable diseases: results of a community-based study in Kerala, India. Indian J Med Res. 2010;131:53e63.

23. Ng N, Stenlund H, Bonita R, Hakimi M, Wall S, Weinehall L. Preventable risk factors for noncommunicable diseases in rural Indonesia: prevalence study using WHO STEPS approach. Bull World Health Organ. 2006;84:305e313.

24. Hoang VM, Byass P, Dao LH, Nguyen TK, Wall S. Risk factors for chronic disease among rural Vietnamese adults and the association of these factors with sociodemographic variables: findings from the WHO STEPS survey in rural Vietnam, 2005. Prev Chronic Dis. 2007;4:A22.

25. Ong KL, Cheung BM, Man B, Lau CP, Lam KSL. Prevalence, awareness, treatment, and control of hypertension among United States adults 1999e2004. Hypertension. 2007;49:69e75.

26. Cowie CC, Rust KF, Byrd-Holt DD, et al. Prevalence of diabetes and impaired fasting glucose in adults in the U.S. population: National Health and Nutrition
Examination Survey 1999e2002. Diabetes Care. 2006;29:1263e1268.

27. Prevalence and extent of dyslipidemia and recommended lipid levels in US adults with and without cardiovascular comorbidities: the National Health and Nutrition Examination Survey 2003e2004. Am Heart J. 2008;156:112e119.

28. The Cardiological Society of India Kerala Chapter. Coronary Artery Disease and its Risk Factors Prevalence Study (CSI Kerala CRP Study). 2011 unpublished data. 